\title{
Impact Loading on Material Composite Polymeric Foam Reinforced by Bagasse Fibers
}

\author{
Zainal Arif ${ }^{1,2}$, Husaini $^{1,3^{*}}$, Nurdin Ali ${ }^{1,3}$, Sri Mulyati ${ }^{1,4}$ \\ ${ }^{1}$ Doctoral Program, School of Engineering, ${ }^{2}$ Department of Mechanical Engineering, ${ }^{3}$ Department of Mechanical Engineering, \\ ${ }^{4}$ Department of Chemical Engineering \\ ${ }^{1,3,4}$ Universitas Syiah Kuala, ${ }^{2}$ Universitas Samudra \\ Aceh, Indonesia \\ *husainiftm@unsyiah.ac.id
}

\begin{abstract}
Bagasse is produced of waste from the processing of sugar cane into sugar. This waste is wasted a lot, so it is necessary to treat this waste to become a composite material to increase its economic value. At the same time, it can overcome the handling of waste products. Impact loading test on the composite material needs to be investigated to obtain a composite polymeric foam material with a better impact strength. This study aims to obtain the impact energy value on a composite polymeric foam material with waste bagasse fibers as reinforcement due to Charpy impact loading. The Bagasse is mixed with resin and foamed polymer foam and a catalyst to accelerate the chemical reaction to produce a new polymer composite material with bagasse fibers reinforcement. The mesh size used is Mesh 40 with a composition of different materials. From the impact test data, it can be concluded that the energy value of the impact load that this composite material can accept is $\mathbf{1 7 6 . 5 3 5}$ Joules.
\end{abstract}

Keywords-impact loading, composite material, polymeric, foam, bagggase fibers

\section{INTRODUCTION}

Composite materials science has continued to evolve in recent years [1]. This research has attracted researchers and the user of composite materials [2]. The continuous research series has the aim of obtaining an excellent composite material [3] and placing it according to its function [4], and gradually the use of metal dominance decreases [5]. The processing and mixing of two or more composite science materials have different physical and chemical properties from each other [6]. The mixing process is carried out macroscopically [7] so that the new material produced has much better strength than the mixture of raw ingredients [8], and the original properties of the original material will remain evident [9].

Developed countries have previously researched and developed composite fillers [9]. Its development uses synthetic materials, such as carbon fiber, rubber, plastic, and other materials [10]. However, the use of synthetic fibers in composites requires a relatively expensive process cost [11]. Other than that, it is hazardous for health and the environment
[12]. Natural fibers that are an alternative to synthetic fibers can be sourced from plants or animals. Natural fibers utilize natural fibers as a renewable resource such as palm oil, hemp fiber, kapok fiber, seed fiber, sugarcane fiber, and banana fiber [12] produces suitable composite materials [2]. The research of natural fiber has received much attention in recent years. Besides the relatively low processing price, easy to obtain, harmless, natural materials are also environmentally friendly [13]. The use of natural fibers (not synthetic or human-made) needs to be further developed [14].

Natural fiber-based composites are composite materials consisting of polymers that function as a matrix, usually can be categorized into two, namely: thermoplastic [15] and thermoset [6]. Meanwhile, natural fibers have good strength, which functions as reinforcement such as hemp, palm oil, sisal, kenaf, hemp, Bagasse [7].

The fibers used in composite materials have the advantage of being isotropic fibers [16]. This fiber has a very high mechanic strength [17]; also, exceptional stiffness can be obtained [18] and is technically a natural fiber that is more flexible [19] and superior to glass fibers in automobile applications in the event of a collision [20].

Polymer composites using polymer foam have been widely used in composite applications, and according to 2013 data, their usage is close to 19 million tons. Moreover, by 2019, these foamed polymers' composite demand will increase by 25 million tons [6]. Foamed polymer consumption predicts an increase in the coming years [7]. In construction applications, this polymer foam is widely used because of its excellent mechanical properties and thermal [21]. Furthermore, a solid polyurethane foam (PU) application is mainly used for thermal insulation, packaging, coating, construction [22], automotive, and other applications [23].

Many researchers have carried out previous research on this composite material, such as that conducted by Artur Campos Pereira in 2017. Artur studied the impact of Charpy on composite materials using an epoxy matrix and straw fiber as reinforcement. From his research series, it was found that there 
was an increase in the absorbable impact energy by increasing the amount of hemp by $20 \%$ by volume. The size and impact energy that can be absorbed is 215 Joules [20].

From the research above, the researcher wants to study the amount of energy that the composite material can absorb by using a polyurethane polymer matrix and bagasse fiber as reinforcement. This study also needs a blowing agent to decrease combined weight and expected that materials have better impact strength.

This study aims to obtain the energy Charpy impact on composite polymeric foam material with bagasse fibers reinforcement.

\section{MethodS}

\section{A. Materials}

The composite material is divided into two main parts: binder and filler/ reinforcement material. This reinforced material/ filler comes from local waste in the form of Bagasse. Processing of composite materials to produce polymeric foam agents is requiring blowing agent material such as polyurethane. The final result in the manufacture of composites polymeric foam is depended on: the selection and management of Bagasse, setting, determining the amount of material required, and the process of the steps in stages from start to finish. The next step is very influential in soaking the Bagasse, refining the Bagasse, and enriching and sampling the test material. Fiber is obtained from Bagasse from sugar cane traders around Langsa City in Aceh- Indonesia. The Bagasse is then converted into a fiber, used as a filler and reinforcement for the composite structure material. In this research, the binder functions as a matrix are used as a thermoset polymer (BQTN 157). To decreased the weight of the composite material, a blowing agent is required. A combination of polyol and isocyanate is used as the blowing agent. To ensure that the Bagasse is clean from oil and dirt, $\mathrm{NaOH}$ is added to the water in the bagasse soaking process. Besides, catalysts are used to speed up reactions in composite manufacturing.

This study used a variable weight composition of materials. The variables that can be measured in this case are bagasse fiber and resin, while the other supporting materials are fixed. Two variations in composition were used in this study. Variation one used fiber and the other without fiber. Each variation needs three samples were taken. The results data sample will be used on analysis. This latest research is to determine the effect of adding fiber to composite polymeric foam. Moreover, every sample material is labeled as I1, I2 labeling each variation in the sample composition.

\section{B. The Process of Bagasse Fibers}

Before making the specimens in this research, the initial step is to produce fibers according to the desired size. The process of producing waste bagasse fibers is carried out in several stages. The processing stages can be described, namely: a). The first step is to provide bagasse waste in the container; b). Bagasse soaked in a solution of air and $1 \% \mathrm{NaOH}$; c). Then the Bagasse is cleaned with clean water and dried in the sun; d). Bagasse cut into small pieces (5 to $10 \mathrm{~cm}$ ); e). Crush the Bagasse into small pieces using a fiber crusher to get a fine fiber; f). The fine bagasse fibers are filtered with a size of Mesh 40; g). Fiber is produced.

\section{The Preparation and Process of Specimens}

The technique of producing samples of material composite polymeric foam in this study begins with preparing materials. This composite material is made of polymer type BQTN 157, bagasse fiber, blowing agent, and catalyst. The composition of the elements, each ingredient measure is made according to weighed of the gradient. The initial step is purring polymer material and bagasse fibers into a mixing container and then stir until the parts are evenly mixed. Adding a catalyst was needed when parts are evenly mixed. After a catalyst is evenly mixed, a blowing agent added to the mixing container and stir for a while. The final step is casting the ingredients into a pattern. This method produces polymer composite structures in random and non-continuous fiber directions.

Preparation of the Charpy impact test specimen was carried out by combining the ingredients with a polyurethane polymer as a matrix and bagasse fibers as reinforcement. The specimen was made in two variations: without using bagasse fiber and using bagasse fiber. Specimen Composite code needs to identify the sample test. T-1 is without fiber, and T-2 is using fibers. The Impact test results will be compared amount them. Then the Energy absorbent of each specimen would be analyzed, as the effect of adding fiber and demonstrated by conducting an impact test. It will also be compared with the impact test results carried out by Artur Camposo Pereira, using an epoxy matrix reinforced with hemp fibers.

\section{The Impact Charpy Loading Preparation}

The energy absorbent of composite polymeric foam with bagasse fibers reinforcement needs to test under Charpy impact loadings. Specimens are made by pouring all gradient stuff after mixing them into a pattern using the casting method. The impact Charpy and samples dimension refer according to standard ASTM.

The step of the impact test procedure is: (1). Put the sample to chucks position, (2). Set up and fixed the arm tool to initial high level, (3). Start testing by released arm tool from an initial high level, (4). results data recorded.

\section{RESUlTS AND DISCUSSION}

Results of the production of the specimen for the Charpy impact test can be shown in Figure 1. The matrix used is polymer polyester BQTN 157 and the bagasse fiber as a filler, which serves as reinforcement. Figure 1 shows two variations of the test specimens; without using fiber and using fibers. 

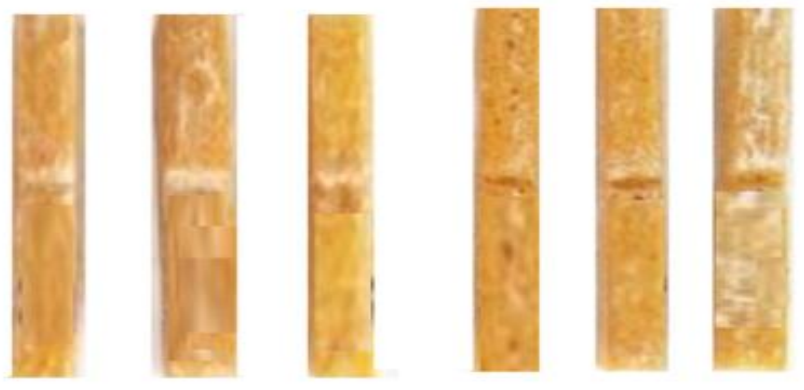

\section{T-1.1 $\quad \mathrm{T}-1.2 \quad \mathrm{~T}-1.3 \quad \mathrm{~T}-2.1 \quad \mathrm{~T}-2.2 \mathrm{~T}-2.3$}

Fig. 1. Charpy impact specimens .

The impact test was performed using the Charpy testing procedure. The first variation test was carried out with test objects with a fiber-free composition. The test data obtained that three test samples with the variation without fibers are shown in Figure 2(a). The maximum energy absorbed from that variation on the test objects is 133.86 Joules, 146.72 Joules, and 154.73 Joules.

(a)

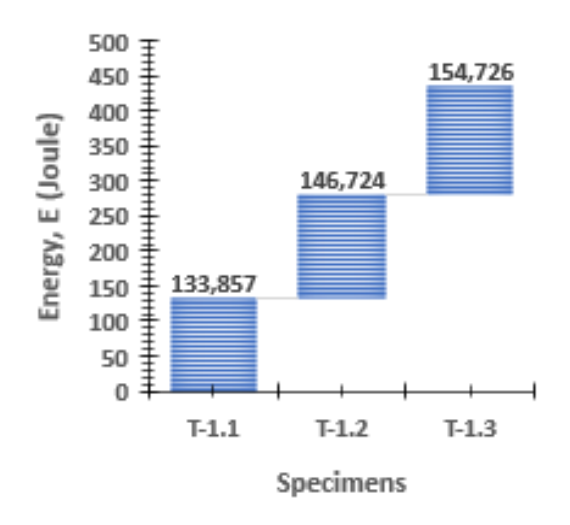

(b)

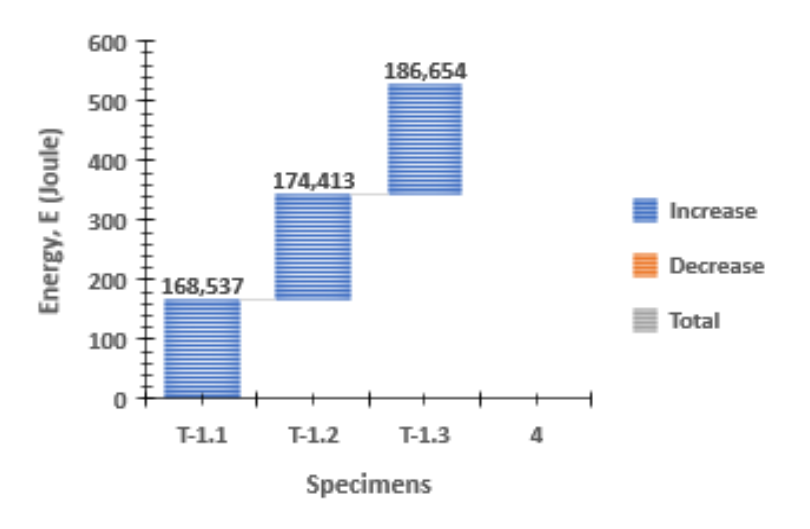

Fig. 2. Energy Charpy Impact Test, (a) without Fibers (b) with Fibers.

While the second step variation test was carried out on the test objects with a fiber composition of $5 \%$ by weight, the second-stage test was obtained from the three test samples using fiber, as shown in Figure 2(b). The maximum energy was absorbed on the test objects; respectively, yields are 168.54 Joule, 174.41 Joule, 186.65 Joule.

Data in figure 2 showed that the average energy was absorbent for each test taken. The average energy value for variations in the specimen's composition without using fibers in the mixture is 145.10 Joules, while the energy value of the variable composition using fibers in the mixture is 176.64 Joules.

In the same test, specimens have been done. Artur Camposo Pereira has evaluated the Charpy impact on composites with an epoxy matrix reinforced by hemp fibers. The maximum strength of that composite obtained by strengthening hemp fibers is around $30 \%$ by volume continuous with aligned jute fibers. It is found that the energy of Charpy impact could be absorbent on that specimen is reached amount $214 \mathrm{~J}$.

When compared with testes was conducted by Artur Camposo Pereira's research, the impact energy on composite polymeric foam with bagasse reinforcement obtained in this test is almost close. The maximum impact energy in the bagasse fiber constituent test reaches 176.6 Joules. The same thing shows some effect on the composite material mixture by adding fibers to the composition variation samples. There are more affected by adding fibers in the composite variation mixture.

\section{CONCLUSION}

This researched testing study has been done. The average energy absorbed to composites polymeric foam occurred are $145.10 \mathrm{~J}$ without bagasse fibers and $176.54 \mathrm{~J}$ with bagasse fibers. The composition data also could be concluded that the same thing shows some effect on the composite material mixture by adding fibers to the composition variation samples.

\section{ACKNOWLEDGMENTS}

The author thanks Samudra University and Syiah Kuala University for joining the research and their support for this research. Furthermore, thanks to all parties who have a care in this research.

\section{REFERENCES}

[1] M.P. Todor, C. Bulei, T. Heput, and I. Kiss, "Researches on the Development of New Composite Materials Complete / Partially Biodegradable Using Natural Textile Fibers of New Vegetable Origin and Those Recovered from Textile Waste," in IOP Conference Series: Materials Science and Engineering, Jan. 2018, vol. 294, no. 1, p. 012021.

[2] M.R. Sanjay, G.R. Arpitha, and B. Yogesha, "Study on Mechanical Properties of Natural - Glass Fibre Reinforced Polymer Hybrid Composites: A Review," in Materials Today: Proceedings, Jan. 2015, vol. 2, no. 4-5, pp. 2959-2967.

[3] H. Mechakra, A. Nour, S. Lecheb, and A. Chellil, "Mechanical Characterizations of Composite Material with Short Alfa Fibers Reinforcement," Compos. Struct., vol. 124, pp. 152-162, 2015. 
[4] C. Barile, C. Casavola, and F. De Cillis, "Mechanical Comparison of New Composite Materials for Aerospace Applications," Compos. Part B Eng., vol. 162, pp. 122-128, 2019.

[5] T.A. Adlie, S. Rizal, N. Ali, S. Huzni, and S. Thalib, "Characterization of Polymeric Foam Composite Reinforced with Empty Fruit Bunch," in IOP Conference Series: Materials Science and Engineering, Jun. 2019, vol. 536, no. 1, p. 012018.

[6] Z. Arif, Husaini, N. Ali, and S. Mulyati, "Study on Mechanical Properties of Composite Polymeric Foams Reinforced by Bagasse Fibers," IOP Conf. Ser. Mater. Sci. Eng., vol. 536, no. 1, p. 012023 , 2019.

[7] Z. Arif, T.A. Adlie, F. Amir, S. Thalib, N. Ali, Nazaruddin, and Mustafa, "Tensile Loading on Composite Polymeric Foam Reinforced by Empty Fruit Bunch Waste (EFB)," Int. Conf. Sci. Technol. Mod. Soc., vol. 1, no. 1, pp. 168-171, 2017.

[8] B. Syam, A. Sebayang, S. Sebayang, M. Muttaqin, H. Darmadi, W. Basuki, M. Sabri, and S. Abda, "Design and Production of Stopper Made of Concrete Foam Composite Used for Open Channel Conduit Cover and Parking Bumper," IOP Conf. Ser. Earth Environ. Sci., vol. 126, no. 1, p. 012053, 2018.

[9] T. Kovář́ik, J. Hájek, M. Pola, D. Rieger, M. Svoboda, J. Beneš, P. Šutta, K. Deshmukh, and V. Jandová, "Cellular Ceramic Foam Derived from Potassium-Based Geopolymer Composite: Thermal, Mechanical and Structural Properties," Mater. Des., vol. 198, p. 109355, 2021.

[10] A. Ashori, M. Ghofrani, M.H. Rezvani, and N. Ayrilmis, "Development and Material Properties of Reinforced Plywood Using Carbon Fiber and Waste Rubber Powder," Polym. Compos., vol. 39, no. 3, pp. 675-680, 2018.

[11] H.M.C.C. Somarathna, S.N. Raman, D. Mohotti, A.A. Mutalib, and K.H. Badri, "The Use of Polyurethane for Structural and Infrastructural Engineering Applications: A State-of-the-Art Review," Construction and Building Materials, vol. 190. Elsevier Ltd, pp. 995-1014, Nov. 2018.

[12] H.E. Emam, R.M. Abdelhameed, and H.B. Ahmed, "Adsorptive Performance of MOFs and MOF Containing Composites for Clean Energy and Safe Environment," J. Environ. Chem. Eng., vol. 8, no. 5, p. 104386,2020

[13] N.A.S. Aprilia, S. Mulyati, P.N. Alam, Karmila, and A.C. Ambarita, "Characterization Nano Crystalline Cellulose from Sugarcane Baggase for Reinforcement in Polymer Composites: Effect of Formic Acid
Concentrations," in IOP Conference Series: Materials Science and Engineering, Apr. 2018, vol. 345, no. 1.

[14] E. Omrani, P.L. Menezes, and P.K. Rohatgi, "State of the Art on Tribological Behavior of Polymer Matrix Composites Reinforced with Natural Fibers in the Green Materials World," Eng. Sci. Technol. an Int J., vol. 19, no. 2, pp. 717-736, 2016.

[15] P.K. Bajpai, K. Debnath, and I. Singh, "Hole Making in Natural FiberReinforced Polylactic Acid Laminates," J. Thermoplast. Compos. Mater., vol. 30, no. 1, pp. 30-46, 2017.

[16] H.S.S. Shekar and M. Ramachandra, "Green Composites: A Review," in Materials Today: Proceedings, Jan. 2018, vol. 5, no. 1, pp. 2518-2526.

[17] C. Elanchezhian, B.V. Ramnath, G. Ramakrishnan, M. Rajendrakumar, V. Naveenkumar, and M.K. Saravanakumar, "Review on Mechanical Properties of Natural Fiber Composites.," in Materials Today: Proceedings, Jan. 2018, vol. 5, no. 1, pp. 1785-1790.

[18] R. Siakeng, M. Jawaid, H. Ariffin, S.M. Sapuan, M. Asim, and N. Saba, "Natural Fiber Reinforced Polylactic Acid Composites: A Review," Polym. Compos., vol. 40, no. 2, pp. 446-463, 2019.

[19] S.N.A. Safri, M.T.H. Sultan, M. Jawaid, and K. Jayakrishna, "Impact Behaviour of Hybrid Composites for Structural Applications: A Review," Composites Part B: Engineering, vol. 133. Elsevier Ltd, pp. 112-121, Jan. 2018

[20] A.C. Pereira, S.N. Monteiro, F.S. de Assis, F.M. Margem, F.S. da Luz, and F. de O. Braga, "Charpy Impact Tenacity of Epoxy Matrix Composites Reinforced with Aligned Jute Fibers," J. Mater. Res. Technol., vol. 6, no. 4, pp. 312-316, 2017.

[21] S.X. Wang, H.B. Zhao, W.H. Rao, S.C. Huang, T. Wang, W. Liao, and Y.Z. Wang, "Inherently Flame-Retardant Rigid Polyurethane Foams with Excellent Thermal Insulation and Mechanical Properties," Polymer (Guildf)., vol. 153, pp. 616-625, 2018

[22] M. Ramesh, "Flax (Linum Usitatissimum L.) Fibre Reinforced Polymer Composite Materials: A Review on Preparation, Properties and Prospects," Prog. Mater. Sci., vol. 102, pp. 109-166, 2019.

[23] Y. Pan, L. Liu, W. Cai, Y. Hu, S. Jiang, and H. Zhao, "Effect of Layerby-Layer Self-Assembled Sepiolite-Based Nanocoating on Flame Retardant and Smoke Suppressant Properties of Flexible Polyurethane Foam," Appl. Clay Sci., vol. 168, pp. 230-236, 2019. 